Southern Methodist University

SMU Scholar

Faculty Journal Articles and Book Chapters

Faculty Scholarship

2017

\title{
Close Encounters: A Feminist Legal Theory Analysis of the State Treatment of Female Child Sexual Abuse Victims
}

Jessica Dixon Weaver

Southern Methodist University, Dedman School of Law

Recommended Citation

Jessica Dixon Weaver, Close Encounters: A Feminist Legal Theory Analysis of the State Treatment of Female Child Sexual

This document is brought to you for free and open access by the Faculty Scholarship at SMU Scholar. It has been accepted for inclusion in Faculty Journal Articles and Book Chapters by an authorized administrator of SMU Scholar. For more information, please visit http://digitalrepository.smu.edu. 


\title{
Close Encounters: A Feminist Legal Theory Analysis of the State Treatment of Female Child Sexual Abuse Victims
}

\author{
Jessica Dixon Weaver ${ }^{1}$
}

\begin{abstract}
This article explores the way in which the law currently deals with sexual violence against female children in the home - evaluating the ways in which the state has access to the private realm of the family and the ways in which civil and criminal legal systems deal with this type of trauma to girls across a spectrum of time. Research shows that the child protection system only captures a small percentage of sexual abuse right after it happens. However, research also shows that female child sex abuse survivors appear in statistically significant numbers among other groups - drug and alcohol abusers, status offenders, domestic violence victims, the sexually trafficked, and juvenile delinquents. The state often has close encounters with these young girls in various settings over the course of their lifetimes - public schools, juvenile delinquency centers, hospitals, jails, mental health institutions, courtrooms, and social service offices. Yet, very few of these systems initially screen for child sexual abuse among females with symptoms indicative of past significant trauma. In the Child Protective Services system, there is a high percentage of mothers who were sexually abused as children and whose children are placed in state foster care. The common denominator in these encounters with both the girl child and the adult woman is this: the perpetrator of the crime against her has suffered little or no consequence for his actions. She, on the other hand, has suffered many subsequent compound issues that negatively affect her life in profound ways.

In an effort to address the cycle of child abuse among families, this article asks a broad question: why hasn't there been a coordinated approach in dealing with the treatment of girls who have been sexually assaulted in the home? Using feminist legal theory, this article argues that the state's multiple encounters with the same female child victim over time are paternalistic and reinforce a sense of helplessness that often perpetuates this cycle of abuse within families. It analyzes the state response regarding information about past crime(s) perpetrated against girls and young women and how this response impacts their ability to heal, become empowered, parent and regain custody of their children. It concludes by offering a new coordinated state framework that can connect the dots between state systems and offer a universal process to address the issue of sexual violence against female children in the home.
\end{abstract}

Keywords: intergenerational abuse, child sexual abuse, feminist legal theory

\footnotetext{
${ }^{1}$ Associate Professor, Southern Methodist University Dedman School of Law, Dallas, Texas
} 
THIS IS A DRAFT. DO NOT CITE THIS WORK WITHOUT EXPLICIT PERMISSION FROM AUTHOR.

\section{An Aha! Moment}

The first time I remember noticing the connection between child sexual abuse and neglectful motherhood, I was representing children in a child welfare case as the guardian and attorney ad litem. The termination of parental rights suit involved a young, poor white mother and her two children, both under the age of four. She had dropped out of high school, experimented with drugs and alcohol, and had a continual string of bad relationships from the time she was sixteen. She could not keep a job, and her relationship with her family (her mother and other family members) was strained. When I received a copy of her psychological evaluation, I was really interested to read it because it usually tells me a good deal about why the parent has been unable to raise their children in a safe environment. After reading the sentence, "[Sarah] was molested as a child by her mother's second husband," I then read all of the negative issues that she experienced in life after that one event. I connected the dots easily from the time of her childhood trauma to the time of the removal of her children based on her neglect. Experience told me that her choices in men heightened the chances that they would be in danger of being physically or sexually abused in the future. Her evaluations did not mention any civil or criminal suit that occurred after her sexual abuse, and I learned that the abuse was not reported. It dawned on me that I was making an assumption that this sexual abuse that had occurred when she was a child was the primary source of the complicated reasons that had led to the neglect of her children. It caused me to reflect on all the other mothers that I had encountered in the child welfare system and their family backgrounds. I did not have to think hard about which other mothers' had had a similar experience. Most of my cases seemed to have the same family history.

One of the most memorable cases I handled regarding the untreated child sexual abuse of a female child involved a young African-American mother with two sons, a nine-year old and a two-year old. They all lived with her mother, though she was away from the house more often than not. After doing the math, I realized that there was only an eleven-year difference between the mother and her oldest son. When my clinical student and I visited the grandmother of the children to find out the circumstances surrounding the pregnancy of her daughter at such a young age, we were told that she spent the night away at a sleepover with one of her classmates. She subsequently turned up pregnant. Incredulously, the grandmother stated that she, nor her family, pursued any legal action against any of the adults who were present in the home where the sleepover took place. It was quickly swept under the rug, with a statement, "[a]ll I cared about was that my daughter was pregnant, and we had to deal with the fact that she was having a child." The mother of the boys never talked about the incident to us, although it was mentioned in her psychological evaluation. I suspected that the grandmother and the mother might not be telling the truth - that perhaps a family member or close friend had in fact sexually assaulted the mother - and that they were covering up to protect someone. Shortly thereafter, the grandmother revealed that she suspected that an adult male cousin had molested her nine-year-old grandson.

As mandatory reporters, we informed CPS, who then conducted a forensic interview. Her grandson was unable to articulate what had happened to him or who had done it. He subsequently was found [by his grandmother, who was appointed as the temporary guardian] attempting to have anal sex with his two-year-old brother. His grandmother then began having psychological problems and sought psychiatric help in order to deal with the multiple incidents of sexual abuse that had occurred to her daughter and grandchildren. It boggled my mind that this issue of sexual abuse had worked its' way through two generations in one family. This cycle of child sexual abuse is far from an anomaly. Research shows that a significant number of the 
mothers of female children who are being psychologically treated for sexual abuse have been sexually abused themselves. ${ }^{2}$

After delving into the social science and psychological research, it is clear that the state encounters these women in various different settings - hospitals, courtrooms, public schools, mental health institutions, and social service offices. I wondered in the case with the elevenyear-old mother whether the hospital inquired about the father of the baby, or whether social services referred the incident to the police for investigation. Without question this was an instance of statutory rape. How is it that there was no justice sought for this child? Moreover, what therapeutic services were offered to the child and the family, and was the utilization of these services dependent on the adult grandmother's cooperation?

A broad question arises when considering the role of the state as the ultimate protector of children under the parens patriae doctrine. Is there a coordinated approach in dealing with the issue of child sexual assault? While legal practitioners, social workers, medical doctors, and therapists deal with the sexual abuse of children within their disciplines, the overarching focus has been on protection of the child victim from further abuse, investigation and prosecution of the perpetrator, and therapeutic treatment for the child and the family. In most states, Child Protective Services, a division of the Department of Health and Human Services, is tasked with investigation of outcries of child sexual abuse and protection of children when their parents have failed to do so. Many cities have child advocacy centers that provide comprehensive services to children and families who have experienced sexual abuse. But what happens when there is no outcry, or when the occurrence comes to the attention of third parties after a long length of time after the initial incident(s)? For many decades, the statistic of 1 in 4 women being sexually assaulted before the age of 18 has been a reality. Yet, it seems as though our legal system as well as our public health and educational systems have failed to create a way to effectively detect child sexual abuse when the prevalence is so high but the outcries are so low.

It is ironic that modern society has found a way to deal with common diseases that cause serious illness among children, like polio, measles, hepatitis A \& B and diphtheria. ${ }^{3}$ What is missing is a comprehensive method to screen for child sexual abuse. It can certainly be argued that the complex effects of this type of trauma are as serious and life threatening as a medical disease. The theory of non-intervention has significantly influenced when and how the state can enter the private realm of the family home to regulate relationships between a husband and wife or parents and children. In the 1970s, the battered woman syndrome brought attention to domestic violence against married women, and over 45 years later there are federal and state laws, protective shelters, police training and policies, and specialty courts to deal with the prevalence of this societal issue. Billboards, movies, television shows and popular media highlight the moral and cultural stance that the women experiencing this abuse are not to be silenced, but validated, vindicated, and released from the prison of mistreatment.

The same women's movement that galvanized to combat domestic violence against wives and girlfriends played a role in breaking the silence surrounding incest and sexual abuse of children by not only family members, but trusted friends in the community. However, what has happened over time with respect to the awareness and treatment of child sexual abuse has not followed the same trajectory of physical abuse of women as partners in a relationship. When there is a sexual abuse outcry by a child, it can definitely be said that progress within the legal system has been made ${ }^{4}$, but there are certain hurdles that have made it difficult for

\footnotetext{
${ }^{2}$ Karen A. Duncan, The Impact of Sexual Abuse on Parenting: A Female Perspective in VISTAS: COMPELLING Perspectives on Counseling 267-70 (G.R. Walz \& R.K. Yep, eds. 2005).

${ }^{3}$ Center for Disease Control, Parents Guide to Childhood Immunizations, available at https://www.cdc.gov/vaccines/parents/tools/parents-guide/downloads/parents-guide-part1.pdf

${ }^{4}$ Erna Olafson, Child Sexual Abuse in SeXuAlized VIOlEnCE AGAINSt Women AND ChILDREN 169 (B.J. Cling, ed. 2004)(noting that the reporting, substantiation, and prosecution of child sexual abuse cases skyrocketed in the 1980s and 1990s, but then began to decline significantly in the 1990s).
} 
criminal convictions to be secured in these cases. Supreme court case Crawford $v$. Washington placed a higher threshold on the availability of a witness to satisfy the Confrontation Clause, causing many child abuse cases to be dismissed due to the inability of the child to testify. Recently the Supreme Court in Ohio v. Clark reassured courts around the country that the statements of a third party, mandated with protection of a toddler, were admissible as evidence to hold a perpetrator of child abuse accountable. However, in order to get to criminal court, there must be an outcry or physical evidence. Research shows that medical, social, and legal, professionals have relied too heavily on the medical examination in diagnosing child sexual abuse. ${ }^{5}$ Only $4 \%$ of all children referred for a medical evaluation of sexual abuse have abnormal evaluations. ${ }^{6}$ On the civil side, there are still a significant number of family law cases where judges award custody to men accused of child sexual abuse. ${ }^{7}$ By far, the most consistent fact shown in studies about child sexual abuse is that it is still not reported to authorities because large percentages of victims never tell anyone about the abuse. ${ }^{8}$

This article asserts that the state turns a blind eye to young girls and women suffering from the educational, mental health, social, and physical effects of sexual abuse over the course of their lifetime. Using a feminist legal theory framework, this article explores the way in which the law currently deals with sexual violence against female children in the home - evaluating the ways in which the state has access to the private realm of the family and the ways in which the legal system deals with this type of trauma to girls across a spectrum of time. This article focuses on the nexus of the state as first responder, collector of information, and often times, prosecutor. It examines several questions: Are these multiple state encounters paternalistic in nature? If so, do they reinforce her feelings of helplessness that began or continued with the sexual abuse she experienced as a child? How do each of these systems currently screen for child sexual abuse? Are there different approaches to this problem that should be implemented in order to heal and empower child sexual abuse victims?

\section{Untreated Sexual Trauma of Female Children}

The problem of untreated sexual trauma of female children is a recurring issue in civil and criminal courts in the United States. Research shows that the child protection system only captures a small percentage of sexual abuse right after it happens. ${ }^{9}$ The correlation between child sexual abuse and a variety of societal maladies is well documented. ${ }^{10}$ The young girls

\footnotetext{
${ }^{5}$ Astrid Heger et al., Children Referred for Possible Sexual Abuse: Medical Findings in 2384 Children, 26 CHILD ABUSE \& NEGLECT 645 - 59 (2002).

${ }^{6}$ Id.

${ }^{7}$ Erna Olafson, supra note 4 at 173.

${ }^{8}$ Id. at 169 .

${ }^{9}$ Gisela Priebe \& Carl Goran Svedin, Child Sexual Abuse is Largely Hidden from the Adult Society: An Epidemiological Study of Adolescents' Disclosures, 32 CHILD ABUSE \& NEGLECT 1095 (2008)(Of the sample, 1505 girls $(65 \%)$ and 457 boys (23\%) reported experience of sexual abuse, and the disclosures made ( $81 \%$ of the girls and $69 \%$ of the boys) were mostly to a friend their own age. Few of the children had disclosed to professionals, and even fewer reported the incident to the authorities); Erin K. Martin \& Peter H. Silverstone, How Much Child Abuse is "Below the Surface," and Can We Help Adults Identify it Early?, 4 FRONTIERS PSYCHIATRY 1, (2013)(noting the data suggests that in over $95 \%$ of cases the child sexual assaults is never disclosed to authorities); National Children's Advocacy Center, Sexual Abuse: Perpetrators, Grooming, and Prevention (June 27, 2014), available at http://www.nationalcac.org/wp-content/uploads/2016/08/Perpetrator Information.pdf (noting 16\% of victims tell).

${ }^{10}$ Robert Maniglio, The Impact of Child Sexual Abuse on Health: A Systemic Review of Reviews, 29 Clinical Psychol. Rev. 647, 650-54 (2009)(noting evidence that survivors of childhood sexual abuse are significantly at risk of a wide range of medical, psychological, behavioral, and sexual disorders). Penelope K. Trickett et al., The Impact of Sexual Abuse on Female Development: Lessons from a Multigenerational, Longitudinal Research Study, 23 DEV. \& PSYCHOPATHOLOGY 453 (2011)(noting that "sexually abused females (on average) showed deleterious sequelae across a host of biopsychosocial domains including: [ ]depression, dissociative symptoms, [] high rates of obesity, more major illnesses and healthcare utilization, dropping out of high school, persistent posttraumatic stress disorder, [] drug and alcohol abuse, and domestic violence"); David M. Fergusson et al., Childhood Sexual Abuse and Adult
} 
who experience this type of violence often grow up to become victims in their own homes as partners or spouses, or within their communities, and a segment of them become neglectful or abusive mothers to their children. ${ }^{11}$ My focus is on women and their children because the prevalence and incidence of child sexual abuse is greater among girls. ${ }^{12}$ Research shows that daughters or women who were sexually abused as children are 3.6 times more likely to be sexually abused themselves compared to daughters of women who were not sexually abused. ${ }^{13}$

These girls, as they mature into women, are encountered in several different state systems after they have been sexually abused as children. Empirical research in the fields of social science, medicine and psychology reveals that the state encounters these women in various different settings - hospitals, courtrooms, public schools, police stations, jails, mental health institutions, and social service offices. ${ }^{14}$ They comprise a statistically significant portion of juvenile offenders, teenage mothers, domestic violence victims, alcohol and drug addicts, and incarcerated adults. ${ }^{15}$ Though there is no public government system that specifically treats alcohol and drug addiction other than the juvenile and criminal justice systems, the child sexual abuse victim is thirteen times more likely to abuse alcohol and twenty-six times more likely to abuse drugs. Another place that they appear in disproportionate numbers is the child welfare system - as mothers of abused and neglected children. ${ }^{16}$ This essentially means that the state may have several encounters with the same child victim over time. However, it does not appear that an entity within the state's machine connects the dots between the interrelated issues encountered by women with a history of childhood sexual abuse and the effect of these issues on motherhood. This failure to comprehensively address the issue of generational child abuse is catastrophic.

Developmental Outcomes: Findings From a 30-year Longitudinal Study in New Zealand, 37 CHILD ABUSE \& NEGLECT 664, 669-72 (2013)(noting that after statistical adjustment for confounding by 10 covariates spanning sociodemographic, family functioning and child factors, the extent of exposure to child sexual assault was associated with increased rates of major depression, anxiety disorder, suicidal ideation, suicide attempt, alcohol dependence, illicit drug dependence); Iris M. Steine et al., Cumulative Childhood Maltreatment and its Dose-response Relation with Adult Symptomatology: Findings in a Sample of Adult Survivors of Sexual Abuse, 65 Child Abuse \& Neglect 99, 10405 (2017)(noting that a sample of adult survivors of child sexual abuse had statistically significant dose-response relation between cumulative childhood maltreatment scores and self-reported symptoms of posttraumatic stress, anxiety, depression, eating disorders, dissociation, insomnia, physical pain, emotional pain, relational problems, selfharm behaviors and lower levels of work functioning).

${ }^{11}$ Pamela Schuetze \& Rina Das Eiden, The Relationship Between Sexual Abuse During Childhood and Parenting Outcomes: Modeling Direct and Indirect Pathways, 29 CHILD ABUSE \& NEGLECT 645 (2005)(noting that child sexual assault was associated with higher maternal depression and higher partner violence. Child sexual assault, maternal depression, and current partner violence were associated with more negative parental perceptions and higher punitive discipline); Susan C. Mapp, The Effects of Sexual Abuse as a Child on the Risk of Mothers Physically Abusing Their Children: A Path Analysis Using Systems Theory, 30 CHILD ABUSE \& NegLeCt 1293 (2006)(sexual abuse as a child was found to impact maternal depression, and maternal depression and locus of control impacted risk of physical abuse).

12 David Finkelhor et al, The Lifetime Prevalence of Child Sexual Abuse and Sexual Assault Assessed in Late Adolescence, 55 J. Adolescent HeAlth 329 (2014); Marije Stoltenborgh et al, A Global Perspective on Child Sexual Abuse: Meta-Analysis of Prevalence Around the World, 16 CHILD MALTREATMENT 79 (2011).

${ }^{13}$ David DiLillo, Interpersonal Functioning Among Women Reporting a History of Childhood Sexual Abuse: Empirical Findings and Methodological Issues, in 21 CLINICAL PSYCHOL.REV. 553, 567 (2001); McCloskey \& Bailey, 2000; Dorthie Cross, Maternal Child Sexual Abuse is Associated with Lower Maternal Warmth Toward Daughters but Not Sons, 25 J. CHILD SeXUAL Abuse 813-26 (2016).

14 Kathleen Kendall-Tackett and Sarah Giacomoni, Child Victimization: maltreatment, bullying, and dating VIOLENCE, PREVENTION AND INTERVENTION (2005).

${ }^{15}$ Kathleen Kendall-Tackett, Treating the Lifetime Health Effects of Childhood Victimization 4-2 - 4-5, 16-2, (2013); K.B. Werner et al., The Association Between Childhood Maltreatment, Psychopathology, and Adult Sexual Victimization in Men and Women: Results from Three Independent Samples, 46 PsychOL. MED. 563-73 (2016).

${ }^{16}$ See generally B.J. Zvara et al., Maternal Childhood Sexual Trauma and Child Conduct Problems, 32 J. FAM. VIOLENCE 231- 42 (2017). 
THIS IS A DRAFT. DO NOT CITE THIS WORK WITHOUT EXPLICIT PERMISSION FROM AUTHOR.

It is vital that a coordinated public health approach for screening child sexual abuse be implemented. Studies show that when screens are put in place, children and adult survivors of child sexual abuse do reveal what has happened to them. ${ }^{17}$ Among adult psychiatric outpatients, a simple questionnaire for the assessment of sexual and physical during childhood and later life revealed that $20 \%$ of patients revealed an experience of sexual abuse during childhood. $^{18}$ The majority of the sexual abuse was committed by the patient's father; $30 \%$ of those $20 \%$ stated that at the time they did not experience the sexual abuse as disturbing; and $30 \%$ of those $20 \%$ stated that they were also victims of sexual violence in adulthood. ${ }^{19}$ In a sample of 571 of children ages 12-17 selected from schools and classrooms in four countries, a child abuse screening tool revealed reports of violence exposure $(51 \%)$, physical victimization $(55 \%)$, psychological victimization $(66 \%)$, and sexual victimization $(18 \%) .{ }^{20}$ The sexual victimization was more prevalent among girls, and the year prior, more children reported sexual abuse $(22 \%) .{ }^{21}$ Pediatricians have also recognized their role in screening for child sexual abuse. $^{22}$ In a recent study of Vermont pediatric health care providers designed to understand the current state of sexual abuse screening in pediatric primary care setting, nurse practitioners were found to be more likely than physicians to routinely screen every child and their caregivers during health supervision visits. ${ }^{23}$ Nurse practitioners reported that the electronic health records prompted these screenings, and time was reported as the greatest barrier to screening and prevention. $^{24}$

Mandatory reporting by professionals passed as part of the Child Abuse Prevention and Treatment Act is a vital part of the identification and treatment of child sexual abuse. The level of technology used today in medical and most professional settings is such that many countries could imbed a child abuse and neglect survey within an electronic health record. Each year during the standard wellness/health check of children under the age of 18, a nurse or physician could inquire about whether a child has been sexually abused. There is obviously the risk that even with this type of survey in place, a child might not report the abuse, and a parent might not either, because he/she does not know about it or does not want to reveal the criminal conduct. The electronic survey might press another problem preventing greater treatment of child sexual abuse -- the unreported cases by professionals with a legal obligation to report. In the past, the first National Incidence Study (NIS) revealed professional underreporting to be a major issue, with 652,000 of identified cases but only 212,400 in CPS agency records. ${ }^{25}$ The reporting gap has declined since the 1980s, but the second NIS still showed that "fewer than half of all cases known to professional were reported to CPS. ${ }^{26}$ Researchers set forth factors related to the professional's ethical decision not to report, including, but not limited to, whether they thought the report was reliable, whether the abuse was serious enough to warrant a report, the race of

\footnotetext{
${ }^{17}$ Rosaleen McElvaney, Disclosure of Child Sexual Abuse: Delays, Non-Disclosure and Partial Disclosure. What Research Tells Us and Implications for Practice, 24 CHILD ABUSE REV. 159, 164-67 (2013).

${ }^{18}$ C.G. Kooiman et al., The Sexual and Physical Abuse Questionnaire (SPAQ): A Screening Instrument for Adults to Assess Past and Current Experiences of Abuse, 26 CHILD ABUSE \& NEGLECT 939, 944 (2002).

${ }^{19} \mathrm{ld}$.

${ }^{20}$ Adam J. Zolotor et al., ISPCAN Child Abuse Screening Tool Children's Version (ICAST-C): Instrument Development and Multi-National Pilot Testing, 33 CHILD ABUSE \& NEGLECT 833-41 (2009).

${ }^{21}$ Id. at 837.

${ }^{22}$ Rochelle F. Hanson \& Cristin S. Adams, Childhood Sexual Abuse: Identification, Screening, and Treatment Recommendations in Primary Care Settings, 43 PRIMARY CARE: CLINICS IN OFFICE PRACTICE 313 - 26 (2016)

${ }^{23}$ Kelley Eileen Groll, Childhood Sexual Abuse Screening and Prevention in The Primary Care Setting: A Survey of Pediatric Healthcare Providers in The State of Vermont (January 2016)(unpublished graduate thesis, University of Vermont).

${ }^{24}$ ld.

25 James Garbarino, Ethical Obstacles to Professional Reporting of Child Maltreatment in PROFESSIONAL

Responsibilities in Protecting Children: A Public Health Approach to Child SeXual Abuse 45 (Ann Maney and Susan Wells, eds. 1988).

${ }^{26}$ Rebecca M. Bolen, Child Sexual Abuse: Its Scope and Our Failure 222 (2001).
} 
the offender, ${ }^{27}$ the job or socio-economic status of the offender, ${ }^{28}$ and whether they believed the child's condition might worsen if a report was made. ${ }^{29}$ The most recent NIS study in 2010 presented information showing that even though schools are the largest source of recognition for maltreated children, only $20 \%$ or less of abused children recognized at schools receive CPS investigation. ${ }^{30}$ One factor identified as contributing to the low investigation rate for schoolrecognized child abuse is school policy barring staff from making direct reports to CPS. ${ }^{31}$

\section{Feminist Legal Theory Analysis of Problem}

The kaleidoscope of feminist legal theory has been utilized to analyze the act of sexual abuse of female children - dominance theory, cultural theory, critical race theory, and even postmodern theory. ${ }^{32}$ Catherine MacKinnon's dominance theory easily explains the power that fathers or men in the family had over women and children. Perhaps it can be argued that the first sexual harassment cases began within the family rather than in the workplace. Judith Herman sets forth those patriarchal families where women and children were treated like property and subservient to men were families in which father-daughter incest occurred. The history of how mothers' reports of child sexual abuse of their female children were treated by doctors in the mid-nineteenth century through the 1940's is replete with incredulous actions by a male-dominated medical industry, ignoring the problem and delegitimize mothers' knowledge about the body, sex and her child. ${ }^{33}$

In analyzing the screening gap that exists in the examination and detection of child sexual abuse, some of the same old narratives that existed in the past influence the actions of those professionals tasked with protecting children. For example, earlier theories of culpability for incest placed blame on the daughter as a seducer and on the mother as being in collusion based on her failure to protect the daughter and assumed abandonment of wifely duties. ${ }^{34}$ When doctors or educators second-guess the reliability of a child's outcry of sexual abuse, they assess the role of the child and the perpetrator, especially based on the age of the child. It is more likely that doctors will report the sexual abuse of a younger child versus a teenager. David Finkelhor found that when a child collaborated with the adult perpetrator, such as by passively accepting sexually abusive behavior, professional judgments of the adult were less harsh. ${ }^{35}$ This finding could be used by MacKinnon to support her current argument for redefining rape because of the gender inequality that the concept of consent presents. ${ }^{36}$ Since there is an inequity in power between a parent and child, there should be no excuse or leniency for parental abuse.

\footnotetext{
27 "[A] report was more likely to be made if the offender was African American (93\% vs. 67\% for Caucasian offenders)." Id. at 223.

28 "[A] case was more likely to be reported when the offender was a carpenter instead of a prominent attorney." Id.

29 Id. at 223-24.

${ }^{30}$ Fourth National Incidence Study of Child Abuse and Neglect (NIS-4), Report to Congress Executive Summary 22 (2010).

${ }^{31}$ Id. (noting that $20 \%$ of school sentinels indicate that their schools do not permit them to make direct report directly to CPS).

32 JUDith HERMAN, FATHER-DAughter INCEST (1981); Challenging Silence (Jan Breckenridge and Lesley Laing, eds. 1999), LYNN SACCO, UNSPEAKABLE: FATHER-DAUGHTER INCEST IN AMERICAN HISTORY (2009);

${ }^{33}$ SACCO, supra note 32 at 157-181 (noting how doctors rewrote how gonorrhea could be contracted in order to protect fathers from being suspected and prosecuted for sexually abusing their daughters).

${ }^{34}$ BOLEN, supra note 26 at 30-31.

35 David Finkelhor \& D. Redfield, How the public defines abuse in CHILD SEXUAL ABUSE (D. Finkelhor, ed. 1984).

${ }^{36}$ Catherine MacKinnon, Rape Redefined, 10 HARVARD L. \& POL. REV. 431, 470(arguing that an international definition of rape ("a physical invasion of a sexual nature, committed on a person under circumstances which are coercive") does not need nonconsent as part of the definition because it is redundant. "Coercion is present because consent is absent." Id.)
} 
False cultural stereotypes and white privilege also play a role in which child abuse reports are made to authorities. Data shows that physicians labeled an injury as child abuse for parents from lower socioeconomic backgrounds rather than middle class or wealthy parents. ${ }^{37}$ Race is still used an important indicator by many professionals in deciding whether abuse occurred. ${ }^{38}$ The influence of past markers for father-daughter incest is still at play. In the last quarter of the nineteenth century, white Americans "reconceptualized gender as a natural function of race and class" -- promoting the idea that respectable white men were intrinsically unable to engage in behavior like incest. ${ }^{39}$ Allegations of child sexual abuse against socially marginalized men were credible because the behavior was expected. ${ }^{40}$

Gender differences likely explain some of the results of the studies mentioned earlier in the paper regarding the screening and reporting of child sexual abuse by medical professionals and teachers, respectfully. Carol Gilligan's work would likely explain why nurses in Vermont more consistently screened for child sexual abuse in the routine medical examinations of children. $^{41}$ If women reason with an ethic of care, while men reason with an ethic of rights, inquiring about child sexual abuse would be seen as necessary by predominately female nurses. Predominately male pediatricians, especially those who may not have as much training in the area of child abuse and neglect, would likely view the sexual abuse screen as invasive of the privacy of families, where men typically preside as head of household. With regard to the policies of some schools that prevent teachers from directly reporting child abuse to state authorities, it is more than likely that the policies were put in place by a male principal. Most teachers are females, and the existence of the policies appears to be justified by a need to screen any reports of child abuse before contacting the state. This type of screen runs the risk of reducing the actual reports of children's outcries based on the same cultural and racial stereotypes doctors have reportedly used. It undermines the legitimacy of female teachers to interpret what their students tell them and removes their power to report what a child has directly told them. In states like Texas, a policy of this nature violates the mandatory reporting laws. Discounting the narratives of women and children works against the legal system set up to help them. Ensuring that their voices are heard is vital to developing a comprehensive system to help victims where they are found locally.

Feminist legal theory helps us to connect the dots between state systems and the people that comprise the first responders. In their role as victim defenders, prosecutors of violent crime can also be part of the comprehensive screening process. While it would cut against postmodern feminist legal theory to assume that all female victims in domestic violence situations are the same, many of the women in the court system do share similar childhood experiences. Simple screens that capture the past history of adult female survivors could help prevent subsequent abuse to a mother and her children. A key part of making such screens valuable for the public would be the availability of therapeutic and psychological treatment for the victim. Any screen designed to capture child sexual abuse would have to be voluntary for the adult victim to complete.

While multiple screens across disciplines might be repetitive, creating a society where asking about child sexual abuse becomes part of the preventative health plan for women is critical to addressing on the various health effects that have been shown to appear. Valid criticisms exist regarding the risk of overreaching into the lives of poor families, as well as exacerbating the disproportionate number of children of color caught up within the child welfare

\footnotetext{
${ }^{37}$ Sharon D. Herzberger, Cultural Obstacles to the Labeling of Abuse by Professionals in PROFESSIONAL Responsibilities in Protecting Children: A Public Health Approach to Child Sexual Abuse 37 (Ann Maney and Susan Wells, eds. 1988).

${ }_{38}$ Id (noting one doctor who explicitly stated that he always looks at race first. Id.).

39 SACCO, supra note 31 at $40-41$.

$40 \mathrm{ld}$. at 41.

${ }^{41}$ See generally Carol Gilligan, In A Different Voice: PSYChOlogical TheORY AND Women's DeVELOPMENT (1982).
} 
THIS IS A DRAFT. DO NOT CITE THIS WORK WITHOUT EXPLICIT PERMISSION FROM AUTHOR.

system. Accounting for bias within the systems and ensuring that private doctors and schools also must comply with the screening is critical. The only way that this could happen is if the screening were a mandate of a federal law. The appropriate law that could be amended to include comprehensive screening is the Child Abuse Prevention and Treatment Act (CAPTA), which provides for mandatory reporting, appointment of attorneys for abused children, and periodic assessment of the problem of child abuse and neglect. If we are to move forward past the silence on this type of abuse, we must provide tools to safeguard the close encounters between the state and adult female survivors and current child victims.

\section{Conclusion}

Child sexual abuse is a complex trauma, legally both civil and criminal in nature. It has been minimized over time because it is can be difficult to prove and hard to treat the entire family when it is interfamilial. The state is not doing enough to address the fact that the majority of children who have been sexually abused do not tell anyone, and when they do, there is not enough done to address the lifetime effects they experience. This article asserts that the reason why the state does not do more to integrate the various systems that deal with adult survivors of abuse is that it would be forced to deal with the gender and racial hierarchies that exist among the professionals tasked with helping the victims. The federal government and states should develop a coordinated approach for the treatment and prevention of child sexual abuse by creating screens across educational, legal, social work, medical and mental health systems that can be electronically documented. Just as society deals with dangerous diseases

with standardized immunizations, a public health approach to capturing untreated female child sexual abuse can be implemented through amending CAPTA. 